\title{
THE SECONDARY LOBULE IN THE ADULT HUMAN LUNG, WITH SPECIAL REFERENCE TO ITS APPEARANCE IN BRONCHOGRAMS *
}

\author{
BY \\ LYNNE REID \\ From the Institute of Diseases of the Chest, Brompton Hospital, London
}

(RECEIVED FOR PUBLICATION NOVEMBER 19, 1957)

Anatomical descriptions of the peripheral part of the lung are varied and inconsistent. They are difficult to relate to bronchographic and radiographic appearances (Twining and Kerley, 1951 ; Fischer, 1953) or to morbid anatomy.

The units in which the periphery has been described may broadly be grouped into two types. The smaller units, measured in millimetres, include those described as the acinus and the primary lobule, and the larger, measured in centimetres, has usually been known as the secondary lobule. To date, attempts to define the secondary lobule have been especially unsatisfactory and, although this paper is concerned primarily with this unit, some preliminary consideration must be given to the smaller units of which it is composed. This smaller unit is concerned with respiratory tissue lying beyond the bronchial tree (Fig. 1), i.e., the alveolar region of the lung.

\section{Smaller Peripheral Unit}

Confusion here arises mainly from the variety of ways in which respiratory tissue has been subdivided for purposes of description. Some of the many names by which this part of the lung has been described are shown in Table I. Because these subdivisions are anatomical they are intrinsically accurate, but misunderstanding arises because the same unit is variously described and the same term applied to different units (see Table I). Perhaps the most useful term is "acinus" (Rindfleisch, 1878 ; Loeschke, 1921), used here to embrace all the respiratory tissue (including respiratory bronchioles, since these have alveoli opening into the lumen) beyond a terminal bronchiole. Lung tissue can thus be divided into the bronchial tree and acini.

\footnotetext{
* A communication based on this paper was delivered to the Thoracic Society in July, 1957.
}

TABLE I

EXAMPLES OF PREVIOUSLY DEFINED UNITS OF PERIPHERY OF LUNG

\begin{tabular}{l|l|l}
\hline \multicolumn{1}{c|}{$\begin{array}{c}\text { Structure Supplying } \\
\text { Unit }\end{array}$} & \multicolumn{1}{c|}{$\begin{array}{c}\text { Name Applied } \\
\text { to Unit }\end{array}$} & $\begin{array}{l}\text { Author by Whom } \\
\text { Name Used }\end{array}$ \\
\cline { 1 - 2 } $\begin{array}{l}\text { Terminal bronchiole } \\
\begin{array}{c}\text { Respiratory bronchiole- } \\
\text { first order or generation }\end{array}\end{array}$ & $\begin{array}{l}\text { Acinus } \\
\text { Plveolar duct }\end{array}$ & $\begin{array}{l}\text { Acinus } \\
\text { Rindfleisch (1878) } \\
\text { Loeschke (1921) } \\
\text { Councilman (1900) } \\
\text { Husten (1921) } \\
\text { Miller (1947) }\end{array}$ \\
\hline
\end{tabular}

\section{LARger Peripheral UnIT}

The previously accepted definition of the secondary lobule is that it is the unit demarcated by septa of connective tissue passing into the lung from the pleura. This simple definition has given rise to the assumption that throughout the lung the septa are uniformly and regularly present; nevertheless various authors in applying the definition have given widely differing estimates of $\delta$ the number of acini which a secondary lobule contains. Rindfleisch (1878) thought that the lobule might include as few as two acini or as many as 30, Berdal (1903) estimated 15 to 18 , 으․ Braus (1924) 12 to 18 , while Laguesse and $N$ d'Hardivillier (1898), whose diagram is still o included in current textbooks, gave as wide a $\tilde{N}$ range as 36 to 100 . Perhaps because of this $\mathcal{\omega}^{\circ}$ embarrassing diversity in the number of acini, 0 more modern accounts (Miller, 1947 ; Birnbaum, 1954) make no reference to them, but describe the lobule in terms of septa only.

The need for applying these anatomical descriptions to radiographs and particularly broncho- $\frac{D}{\mathbb{D}}$


of these inconsistencies and of the difficulty of $\stackrel{\mathbb{Q}}{\square}$ relating the number of acini included to the volume of the secondary lobule. Twining and Kerley (1951) have emphasized how unfortunate 
it is that so much confusion exists at the present time in the nomenclature and description of the finer structures of the peripheral part of the lung.

Reliance on the septa for describing the secondary lobule has been shown to be unjustified. Recent study of the anatomy of the septa in man (Reid and Rubino, 1958) indicates that, by reason of the fact that they vary in their distribution, they are inadequate to define the larger unit. Welldeveloped septa are present only in the subpleural zone; in the deeper part of the lung the connective tissue persists merely as a sheath around the bronchi and large vessels. Furthermore, even in the subpleural region there is a wide variation in the number of septa. This can to some extent be related to the contour of the lung; for example, the septa are relatively frequent over the sharp edges such as the anterior margin and the costodiaphragmatic rim, but sparse over the flatter parts. Moreover, as the septa run at right angles to the pleura any unit they demarcate has no deep boundary. This may account for the disparity in estimates of the number of acini in the secondary lobule and, in particular, for the wide range found by Laguesse and d'Hardivillier (1898), who chose lung from the lateral aspect of the lower lobe to achieve uniformity in their results but, because in this region the septa are sparse, obtained estimates which varied widely and were not representative.

Since the septa are unsatisfactory for defining the secondary lobule the periphery of the lung must be re-examined in the hope of finding some feature which will characterize a unit of reasonably constant size. This unit should be large enough to be useful in the macroscopic description of normal and morbid anatomy and have some distinctive character by which it can be defined. It is noteworthy that in considering size recent authors have usually added to the definition based on the connective tissue septa a rider that the volume of the unit is of the order of one or two cubic centimetres, suggesting thereby that this is appropriate, being macroscopically visible, and, when involved by disease, perhaps detectable radiographically.

This investigation has followed two lines of enquiry ; the first, the distribution of cartilage, and second, the application of the two patterns of bronchial branching, which have been recognized at the periphery in a bronchogram and described by Reid and Simon (1958). For convenience these have been called the "centimetre" and the "millimetre" patterns respectively, these measurements giving approximately the distances between successive branches at the particular level of the bronchial tree. The bronchographic study described in the first part of the previous paper was part of the larger enquiry undertaken to redefine the secondary lobule. A bronchogram has the advantage over other methods of examination that it gives a three-dimensional representation of the bronchial tree in the living subject, and, furthermore, by relating the secondary lobule to the bronchographic appearance, enables the unit to be recognized clinically.

\section{Material AND MethodS}

Considerable post-natal growth takes place in the human lung (Broman, 1923; Willson, 1928), and as the increase in the number of generations occurs in the region of the terminal bronchioles, in describing the secondary lobule it is not possible to argue from the foetal lung to that of the adult; consequently, adult lungs were used except in one case.

The method of investigation included:

(1) The study of clinical bronchograms, the preparation of bronchograms on lung specimens and histological correlation of shadow with structure (see previous paper).

(2) The study of blocks of lung cut serially. Some of these were from injected lungs and are included in the account of the bronchographic studies, but, in addition, blocks of normal uninjected lung were used. In total, 10 blocks of tissue were taken from six adult lungs (three female and three male) of ages ranging from 33 to 71 , and three blocks from a boy of 6 years. These examples included lung from upper and lower lobes, from the hilum and from near the diaphragm, and in all the results were the same. These blocks were usually $3 \times 4 \mathrm{~cm}$. in cross-section and up to $1 \mathrm{~cm}$. deep, so that each would be expected to include several units about $1 \mathrm{c} . \mathrm{cm}$. in volume. The lungs were inflated and fixed by allowing formalin to run into them through the bronchial tree. The interval between sections varied; in some series it was only $0.03 \mathrm{~mm}$. while in others it was $0.25 \mathrm{~mm}$. These sections were most usefully studied at a magnification of 10 or 20 , a plate microscope making it possible at these magnifications to examine a field of $8 \mathrm{~mm}$. or $3 \mathrm{~mm}$. diameter.

(3) The examination of the peripheral part of neoprene casts of the bronchial tree, the part which is generally pared away as it hides the proximal bronchi, the usual focus of interest. These delicate casts could be studied with a hand lens or with the naked eye. In particular, a cast of a male of 56 was used for detailed study.

(4) Bronchial pathways were dissected in normal lung. This did little to elucidate the finer structural details, but it served to relate the histological to the macroscopic appearance of this part of the lung. 


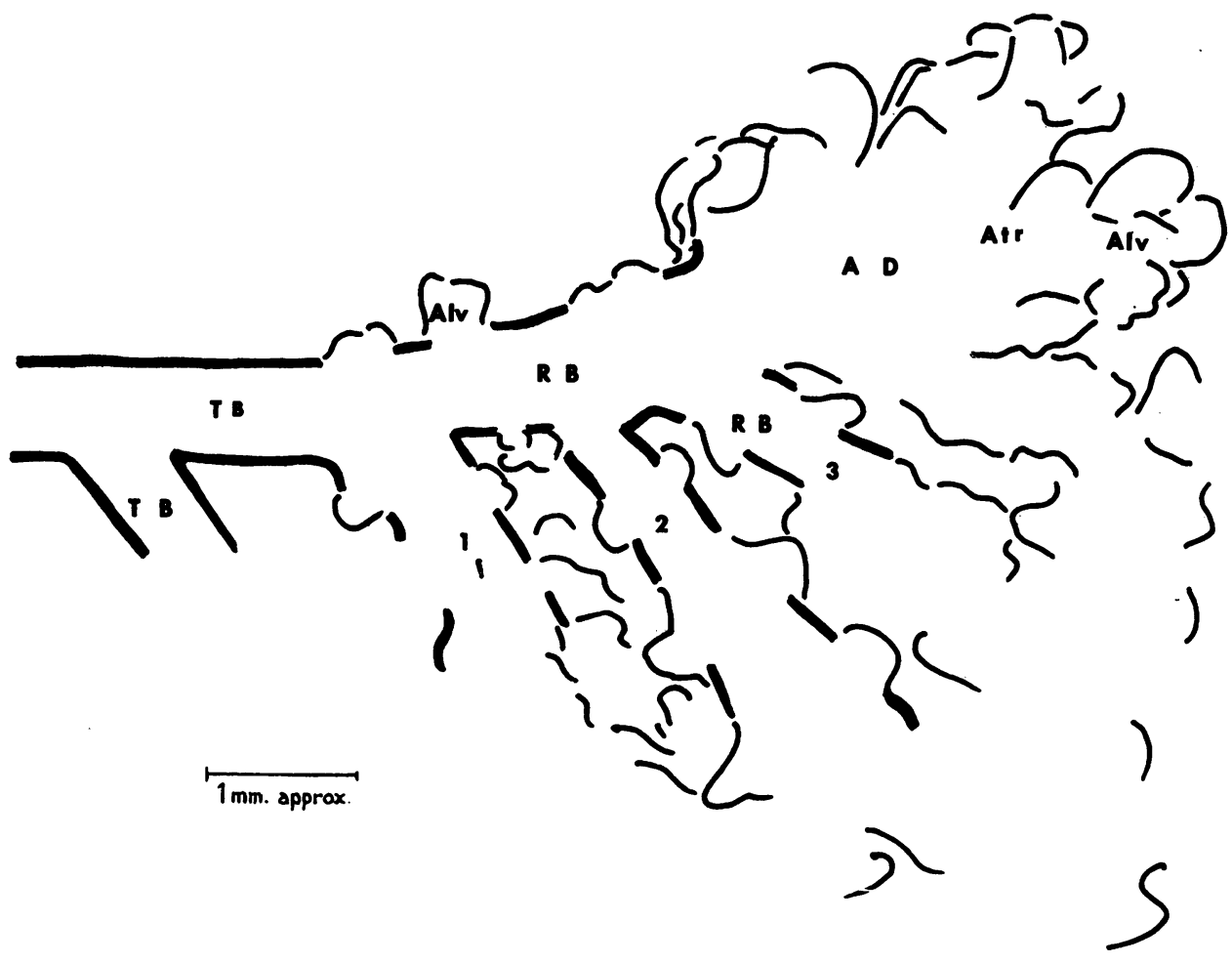

Fig. 1.-Diagrammatic representation of the lung periphery including the terminal bronchiole (TB) and beyond it three generations of respiratory bronchioles (RB), alveolar duct (AD), atria (Atr.), and alveoli (Alv.).

\section{Relation of LaRger Unit to Distribution of Cartilage}

In his study of the secondary lobule Felix (1928) stated that cartilage is not present along bronchial pathways within the lobule but is present in the supplying bronchiole. Examination of serial sections has shown, however, that to take as the beginning of the lobule the point at which cartilage ends is to admit too wide a variation in size. For example, in one series of sections cartilage was within four generations of the pleura, perhaps as close as $7 \mathrm{~mm}$., although in another pathway it was not present within the peripheral two or three centimetres, that is, the last seven or eight branches of this particular pathway were free of cartilage. in the first instance approximately four terminal bronchioles would be included in the unit, in the second upwards of 20 . Where the cartilage was closer to the pleura the section was from the apical segment of the lower lobe, while in blocks from both the lingula and the basal segments it was more than $2 \mathrm{~cm}$. from the pleura. Thus the distribution of cartilage is not a satisfactory criterion for the definition of the secondary lobule.

\section{RELATION OF LARGER UNIT TO BRONCHIAL Branching (CENTIMETRE AND Millimetre PATTERNS)}

The centimetre and millimetre patterns which have been observed in bronchographic investigation of the lung periphery are also recognizable in serial sections, in casts, and microscopic dissections. It has been possible to distinguish both patterns along the distal half of an axial pathway, the beginning of the millimetre pattern coinciding with the first terminal bronchiole. For example, tracing a particular pathway back toward the hilum (Fig. 2a) through two contiguous blocks of lung in sections cut serially and parallel to the pleura showed that four terminal bronchioles arose from branch A about $1.5 \mathrm{~mm}$. apart (millimetre pattern) and then after $6 \mathrm{~mm}$. another branch $B$ gave rise to three terminal bronchioles. A further two branches (C and D) arose from opposite sides of the central pathway, $C$ being separated from both $B$ and $D$ by about half a centimetre.

A variation of the centimetre pattern is shown in Fig. $2 b$, where $B$ and $C$ arose close to each other, but from opposite sides of the central path- 
Pleura

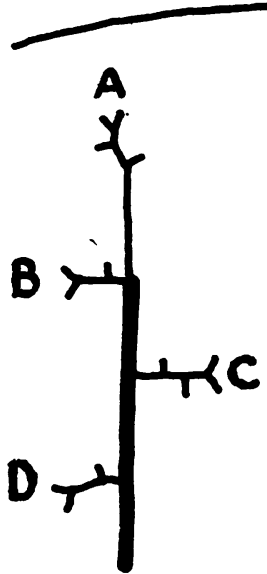

(a)

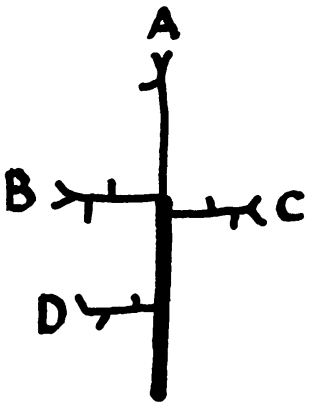

(b)

FIG. 2.-Illustrates variation in the arrangement of the centimetre pattern. In (a), pathways $A, B, C, D$ are separated by $0 \cdot 5-1 \mathrm{~cm}$., each pathway giving rise to three or four terminal bronchiolesthe millimetre pattern. In (b), $B$ and $C$ arise within 1 to $2 \mathrm{~mm}$.
Suggested Definition of Secondary Lobule in Terms of Centimetre and Millimetre Patterns

The change in the pattern of branching of the bronchial tree suggests that, subject to suitability and constancy of size, this transition from the centimetre to the millimetre pattern of branching might be taken as the beginning of the secondary lobule. At the end of a pathway three, four, or five terminal bronchioles may be found, as in the arrangement shown in Figs. 3a, 3b, and 3c. In these examples the terminal bronchioles are shown arising from a central pathway, bronchiole $A$, the bronchiole supplying the secondary lobule from which terminal bronchioles arise. Each of these arrangements constitutes a unit with a diameter of the order of $1 \mathrm{~cm}$., allowing $2 \mathrm{~mm}$. as the distance between branches and $5 \mathrm{~mm}$. as the depth of respiratory tissue beyond a terminal bronchiole. The unit so defined is therefore suitable for macroscopic study.

However, the above description needs some qualification. Sometimes it is valid and useful to way, each giving rise to four t e r m in a l bronchioles; but, although $B$ and $C$ are only 2 mm., rather than half a centimetre or more, apart, they are different from the more peripheral bronchioles, which also are at $2 \mathrm{~mm}$. intervals but are only about $2 \mathrm{~mm}$. long and are terminal bronchioles. When in the centimetre pattern two branches arise within approximately $2 \mathrm{~mm}$. of each other, they usually pass in opposite directions and may subdivide many times before finally giving rise to terminal bronchioles. The interval between the centimetre pattern branches tends to be less, the closer they are to the periphery.

The distance from the origin of the bronchiole supplying a lobule to its first branch varies considerably ; it may be as little as one or two millimetres or as much as a centimetre. Such differences reflect the arrangement of the bronchial tree in relation to the shape of the lung it supplies.

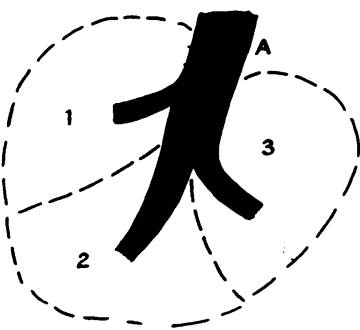

(a)

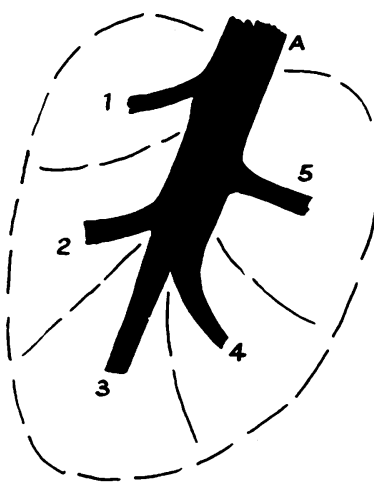

(c)

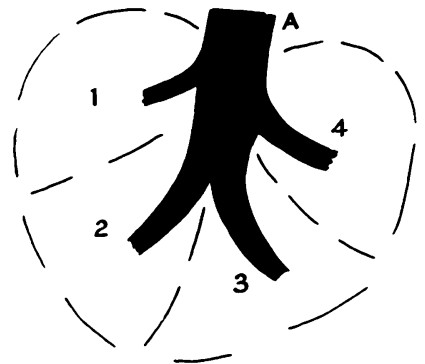

(b)

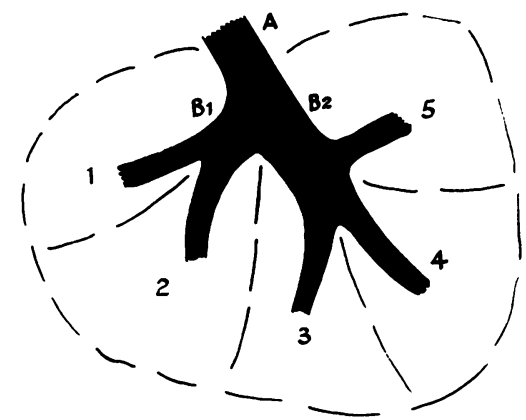

(d)

FIG. 3.-Illustrates variation in the arrangement of the terminal bronchioles around the end of a bronchial pathway, that is, within the secondary lobule. The thin solid lines represent terminal bronchioles, the thick solid lines the bronchiolar pathways, within a secondary lobule, from which terminal bronchioles arise. The acinus supplied by each terminal bronchiole is represented by a broken line. 
include in the unit a cluster of four or five acini even though they derive from a forked pathway as in Fig. 3d, for the reason that a unit of only two acini, $B_{1}$, would seem too small to be of practical value. The difference in the arrangement of the acini, within a similar volume, does not invalidate the description of this cluster as the millimetre pattern at the end of a particular pathway. Thus in Fig. $3 \mathrm{~d}, \mathrm{~A}$ is still the bronchiole to the lobule, but the terminal bronchioles arise from its branches $B_{1}$ and $B_{2}$, the central pathway being forked rather than single as in Figs. $3 \mathrm{a}$ and $3 \mathrm{c}$. Further justification for regarding the whole group in Fig. $3 \mathrm{~d}$ as a unit is that a pathway with only two terminal bronchioles is not usually found separated from adjacent pathways by as much as 0.5 to $1 \mathrm{~cm}$; that is, it is not a separate branch within the centimetre pattern. The variation in arrangement may be due to the shape of the particular part of lung which the respective bronchioles supply.

Diagrams such as these give an incomplete picture of the arrangement of the bronchioles within a volume of lung, as any pathway may turn, even through a right angle, at each point of division. Nevertheless the volume of each unit probably lies between 1 and $2 \mathrm{c} . \mathrm{cm}$.

Number of Terminal Bronchioles Within a Secondary LobULE.-As has been mentioned, the number of terminal bronchioles clustered around the end of a particular pathway varies between three and five. Four was the most usual number in this series. For example, in a neoprene cast, of 26 lobules studied under low magnification, 13 had four terminal bronchioles, eight had five, and five only three. In serial sections of secondary lobules (16 blocks of tissue from seven subjects) 40 pathways were examined and here also the most common number of terminal bronchioles was four, though occasionally there were three or five.

\section{CONCLUSION}

It is suggested that the secondary lobule of the lung can usefully be redefined as the cluster of three to five terminal bronchioles and their associated respiratory tissue, sited at the end of a bronchial pathway - a unit recognizable anatomically and bronchographically. Any bronchus traced towards the alveoli along either direct or side branches will be found to end in such a cluster. The terminal bronchioles supplying this unit, which is of approximately $1 \mathrm{~cm}$. in diameter in the adult, may derive from a single or, less frequently, from a forked, central pathway, and cartilage may extend to the origin of the bronchiole to the lobule or it may have stopped several branches earlier. In the peripheral part of a bronchogram two patterns of branching have been recognized, the centimetre and the millimetre patterns, the finer, shorter, lines of which can be shown histologically to represent these groups of three to five terminal bronchioles, the secondary lobule according to the suggested definition.

Just as the pattern of the bronchial tree, related to the size and topography of the lung to which a particular bronchus is distributed, is the determinant of the broncho-pulmonary segment, so the pattern of branching of the peripheral part of the bronchial tree in relation to the volume of respiratory tissue it supplies determines the unit described as the secondary lobule. Variation in the shape and size of the lobes of the lung involves variation in the shape and size of secondary lobules. Nevertheless the definition proposed here facilitates the recognition of a unit which has practical application in macroscopic, microscopic, and bronchographic studies of the lung.

\section{SUMMARY}

Previous authors have defined the secondary lobule of the lung by reference to connective tissue septa, but, in view of the irregular distribution of the septa in the human lung, this criterion is unsatisfactory. Two possible alternative criteria of definition were examined. The first, the distribution of cartilage, was found unsatisfactory, since the level at which cartilage ends in the bronchial tree is too variable. The other, the transition from the centimetre to the millimetre pattern of branch ing as shown in a bronchogram, was found to define a volume of lung displaying a relatively constant pattern of structure and of a size convenient for macroscopic, microscopic, and bronchographic study. Thus the definition is proposed that the secondary lobule consists of the discrete cluster of three to five terminal bronchioles, with their respiratory tissue, which arise from the end of a bronchial pathway, usually at intervals of about $2 \mathrm{~mm}$. from each other and arranged about a single or forked central pathway.

I should like to thank Dr. David Brown of Charing Cross Hospital Medical School for making neoprene casts of the lung available to me for study and $\mathrm{Mr}$. Denis Kemp. Institute of Diseases of the Chest, for preparing the illustrations. 


\section{REFERENCES}

Berdal, H. (1903). Nouveaux Elements d'Histologie Normale, 6th ed. (Quoted by Miller.) A. Maloine, Paris.

Birnbaum, G. L. (1954). Anatomy of the Bronchovascular System. Year Book Publishers, Chicago.

Braus, H. (1924). Anatomie des Menschen, bd. 2, p. 193. Berlin.

Broman, I. (1923). Anat. Anz., 57, 83.

Councilman, W. T. (1900). J. Boston Soc. med. Sci., 4, 165.

Felix, W. (1928). Anatomie der Lungen. In Chirurgie der Brustorgane, by F. Sauerbruch, Vol. 1, p. 1. Springer, Berlin.

Fischer, F. K. (1953). In Roentgen-Diagnostics by H. R. Schinz, W. E. Baensch, E. Friedl, and E. Uehlinger. English translation by J. T. Case. Vol. 3, p. 2036. Heinemann, London.
Husten, K. (1921). Beitr. path. Anat., 68, 496.

Laguesse, E., and d'Hardivillier, A. (1898). Sur la Topographie du Lobule Pulmonaire. Bibliographie Anatomique.

Loeschke, H. (1921). Beitr. path. Anat., 68, 213.

Miller, W. S. (1947). The Lung, 2nd ed. Thomas, Springfield, Illinois.

Reid, L. M., and Rubino, M. (1958). Thorax. To be published. and Simon, G. (1958). Thorax, 13, 103.

Rindfleisch, E. (1878). Lehrbuch der pathologischen Gewebelehre, 5th ed. Engelmann, Leipzig.

Twining, E. W., and Kerley, P. (1951). In A Text-Book of X-Ray Diagnosis by British authors, 2nd ed., vol. 2, p. 208, edited by S. C. Shanks and P. Kerley. Lewis, London.

Willson, H. G. (1928). Amer. J. Anat., 41, 97. 